\title{
Facile Preparation of Fluoroalkyl End-Capped Vinyltrimethoxysilane Oligomer/Sand Composites Possessing Superoleophilic/Superhydrophobic Characteristic: Application to Oil/Water Separation and Selective Removal of Fluorinated Aromatic Compounds from Aqueous Methanol Solution
}

\author{
Hideo Sawada1 ${ }^{*}$, Kako Tono², Katsumi Yamashita1 \\ ${ }^{1}$ Department of Frontier Materials Chemistry, Graduate School of Science and Technology, Hirosaki University, Hirosaki, Japan \\ ${ }^{2}$ Department of Frontier Materials Chemistry, Faculty of Science and Technology, Hirosaki University, Hirosaki, Japan \\ Email: ^hideosaw@hirosaki-u.ac.jp
}

How to cite this paper: Sawada, H., Tono, K. and Yamashita, K. (2022) Facile Preparation of Fluoroalkyl End-Capped Vinyltrimethoxysilane Oligomer/Sand Composites Possessing Superoleophilic/Superhydrophobic Characteristic: Application to Oil/Water Separation and Selective Removal of Fluorinated Aromatic Compounds from Aqueous Methanol Solution. Open Journal of Composite Materials, 12, 56-71. https://doi.org/10.4236/ojcm.2022.121005

Received: December 15, 2021

Accepted: January 27, 2022

Published: January 30, 2022

Copyright $\odot 2022$ by author(s) and Scientific Research Publishing Inc. This work is licensed under the Creative Commons Attribution International License (CC BY 4.0).

http://creativecommons.org/licenses/by/4.0/ (c) (i) Open Access

\begin{abstract}
Fluoroalkyl end-capped vinyltrimethoxysilane oligomer

$\left[\mathrm{R}_{\mathrm{F}}-\left(\mathrm{CH}_{2}-\mathrm{CHSi}(\mathrm{OMe})_{3}\right)_{n}-\mathrm{R}_{\mathrm{F}}: n=2,3, \mathrm{R}_{\mathrm{F}}=\mathrm{CF}\left(\mathrm{CF}_{3}\right) \mathrm{OC}_{3} \mathrm{~F}_{7}: \mathrm{R}_{\mathrm{F}}-(\mathrm{VM})_{n}-\mathrm{R}_{\mathrm{F}}\right]$, was applied to the facile preparation of the corresponding oligomer/sand (Ottawa sand: OS) composites $\left[\mathrm{R}_{\mathrm{F}}-\left(\mathrm{VM}-\mathrm{SiO}_{3 / 2}\right)_{n}-\mathrm{R}_{\mathrm{F}} / \mathrm{OS}\right]$ through the sol-gel reaction of the oligomer in the presence of micro-sized OS particles $(590-840 \mu \mathrm{m})$ under alkaline conditions at room temperature. FE-SEM (Field Emission Scanning Electron Micrograph) images showed that the obtained composites consist of the $\mathrm{R}_{\mathrm{F}}-\left(\mathrm{VM}-\mathrm{SiO}_{3 / 2}\right)_{n}-\mathrm{R}_{\mathrm{F}}$ oligomeric nanoparticles and the micro-sized OS particles. Interestingly, the $\mathrm{R}_{\mathrm{F}}-\left(\mathrm{VM}-\mathrm{SiO}_{3 / 2}\right)_{n}-\mathrm{R}_{\mathrm{F}} / \mathrm{OS}$ composites thus obtained can provide the superoleophilic/superhydrophobic characteristic on the composite surface, applying to the separation of not only the mixture of oil/water but also the W/O emulsion to isolate the transparent colorless oil. The fluorinated oligomeric OS composites were also found to be applicable to the selective removal of fluorinated aromatic compounds from an aqueous methanol solution. Especially, it was demonstrated that the fluorinated OS composites can supply a higher efficient and smooth separation ability for the separation of the mixture of oil and water than that of the corresponding fluori-
\end{abstract}


nated micro-sized controlled silica gel $\left(\mu-\mathrm{SiO}_{2}\right)$ composites (average particle size: $9.5 \mu \mathrm{m}$ ), which were prepared under similar conditions. In addition to the separation of oil/water, the fluorinated OS composites provided higher and more selective removal ability for the fluorinated aromatic compounds from aqueous solutions than that of the $\mu-\mathrm{SiO}_{2}$ composites.

\section{Keywords}

Fluorinated Oligomeric Composite, Micro-Sized Ottawa Sand Particle, Superoleophilic/Superhydrophobic Property, Smooth Separation of Oil and Water, Selective Removal of Fluorinated Aromatic Compound

\section{Introduction}

Due to the serious problems related to oil spill accidents in the environment induced by the disasters in living systems and a growing body of occurrence of industrial oily wastewater, oil/water separation has been the subject of practical research of the world [1] [2] [3] [4]. In fact, there has been a large volume of reports on the development of the functional materials with superhydrophobic/superoleophilic surfaces to separate the mixture of oil and water [5] [6] [7] [8]. From the practical point of view, it is of particular importance to fabricate the low-cost materials possessing higher efficiency and fast separation ability of oil/water. It is well-known that micro-sized silica gel particles can supply a wide range of practical use such as adsorbents and the packing material for column chromatography. Thus, the practical application of micro-size silica gels to the superhydrophobic/superoleophilic composites is of great significance owing to the development of novel materials for the separation of oil and water, because silica gels are in general low-cost popular materials. In fact, we have recently reported on the preparation of the fluoroalkyl end-capped oligomeric micro-sized silica gel composite particles possessing superoleophilic/supeherhydrophobic characteristic to separate the mixture of oil and water [9].

In addition to the serious problems in increasing environmental pollution related to the oil spill into the ocean as indicated above, a large volume of fluorinated drugs and pesticides have recently come to the market, and made up about $20 \%$ of the pharmaceuticals and over $30 \%$ of all agrochemicals, respectively [10][15]. Therefore, it is deeply desirable to develop the practical removal technologies of not only the oils but also the fluorinated organic micropollutants including their raw materials and intermediates from industrial wastewater. The main component of sand is silicon dioxide, quite similar to that of the silica gel, and sand is also an abundant natural resource. Therefore, the sand should become a good candidate for novel composite materials for the practical removal of oil from wastewater, due to its low cost and nontoxicity to the environment, excellent chemical and physical stability. In fact, attractive attention has been recently focused on the sand composites possessing superhydrophobic characteristic, which can be 
fabricated by the reactions of $1,1,1,3,3,3$-hexamethyldisilazane [16], $1 H, 1 H$, $2 \mathrm{H}, 2 \mathrm{H}$-perfluorodecyltrichlorosilane [17], $1 \mathrm{H}, 1 \mathrm{H}, 2 \mathrm{H}, 2 \mathrm{H}$-perfluorooctyltriethoxysilane [18], octadecyltrichlorosilane [19] [20], and hexadecyltrimethoxysilane [21] [22] with the corresponding sands.

During a growing body of our studies on the two fluoroalkyl end-capped oligomers $\left[\mathrm{R}_{\mathrm{F}}-(\mathrm{M})_{n}-\mathrm{R}_{\mathrm{F}} ; \mathrm{R}_{\mathrm{F}}=\right.$ fluoroalkyl group; $\mathrm{M}$ : radical polymerizable monomers] [23] [24] [25], we have already reported that two fluoroalkyl end-capped vinyltrimethoxysilane oligomer $\left[\mathrm{R}_{\mathrm{F}}-\left(\mathrm{CH}_{2} \mathrm{CHSi}(\mathrm{OMe})_{3}\right)_{n}-\mathrm{R}_{\mathrm{F}}, n=2,3: \mathrm{R}_{\mathrm{F}}-(\mathrm{VM})_{n}-\mathrm{R}_{\mathrm{F}}\right]$ can form the nanometer-sized controlled self-assembled molecular aggregates in organic media such as methanol through the aggregation of terminal fluoroalkyl groups [26]. These fluorinated aggregates interact with a variety of guest molecules [Guest] such as gold nanoparticles, hydroxyapatite, zinc oxide and titanium oxide to provide the corresponding fluorinated oligomeric silica/Guest nanocomposites $\left[\mathrm{R}_{\mathrm{F}}-\left(\mathrm{CH}_{2} \mathrm{CHSiO}_{3 / 2}\right)_{n}-\mathrm{R}_{\mathrm{F}} /\right.$ Guest $]$ possessing not only a surface-active property imparted by fluorine but also a unique characteristic related to each Guest molecule [26]. Therefore, it is of practical interest to prepare the sand composites by the use of the $\mathrm{R}_{\mathrm{F}}-(\mathrm{VM})_{n}-\mathrm{R}_{\mathrm{F}}$ oligomer as a key intermediate. Herein we report on the preparation of fluoroalkyl end-capped vinyltrimethoxysilane oligomer/sand composites $\left[\mathrm{R}_{\mathrm{F}}-\left(\mathrm{CH}_{2} \mathrm{CHSiO}_{3 / 2}\right)_{n}-\mathrm{R}_{\mathrm{F}} /\right.$ sand] by the sol-gel reaction of the corresponding oligomer $\left[\mathrm{R}_{\mathrm{F}}-(\mathrm{VM})_{n}-\mathrm{R}_{\mathrm{F}}\right]$ in the presence of sand particles under alkaline conditions. In addition, we would like to demonstrate on the application of the $\mathrm{R}_{\mathrm{F}}$ $\left(\mathrm{CH}_{2} \mathrm{CHSiO}_{3 / 2}\right)_{n}-\mathrm{R}_{\mathrm{F}} /$ sand composites to the separation of oil and water including the selective removal of fluorinated aromatic compounds from an aqueous methanol solution. These findings will be described in this article.

\section{Experimental}

\subsection{Measurements}

Micrometer size-controlled silica gel composite particles were analyzed by using laser diffraction particle size analyzer: Shimadzu SALD-200 V (Kyoto, Japan). Molecular weight of $\mathrm{R}_{\mathrm{F}}-(\mathrm{VM})_{n}-\mathrm{R}_{\mathrm{F}}$ oligomer was measured by using a Shodex DS-4 (pump, Tokyo, Japan) and Shodex RI-71 (detector) gel permeation chromatography calibrated with polystyrene standard using teterahydrofuran as the eluent. Thermal analyses were recorded by raising the temperature around $800^{\circ} \mathrm{C}$ (the heating rate: $10^{\circ} \mathrm{C} / \mathrm{min}$ ) under atmospheric conditions by the use of Bruker axs TG-DTA2000SA differential thermobalance (Kanagawa, Japan). The contact angles were measured by the use of Kyowa Interface Science Drop Master 300 (Saitama, Japan). Ultraviolet-visible (UV-vis) spectra were measured using Shimadzu UV-1600 UV-vis spectrophotometer (Kyoto, Japan). Field emission scanning electron micrograph (FE-SEM) was recorded by using JEOL JSM-7000F (Tokyo, Japan). Energy dispersive X-ray (EDX) spectra were obtained using JEOL JSM-7000F (Tokyo, Japan). Aluminum crucible (40 mL: Material No: 27311) was purchased from Mettler-Toledo Co., Ltd. (Tokyo, Japan). Ultrasonic irradiation was used by As One Ultrasonic Cleaner US-3R (Tokyo, Japan). Optical and flu- 
orescence microscopies were measured by using OLYMPUS Corporation BX51 (Tokyo, Japan).

\subsection{Materials}

Vinyltrimethoxysilane was used as received from Dow Corning Toray Co., Ltd. (Tokyo, Japan). Sand (Ottawa sand: OS, average particle size: 590 - $840 \mu \mathrm{m}$ ) was received from Restek Corporation (PA, USA). Micro-sized silica particles (Wakogel $^{\mathrm{TR}}$ C-500HG: average particle size: $14 \mu \mathrm{m}$ ) and Acid Blue 112 were supplied from FUJIFILM Wako Pure Chemical Industries (Osaka, Japan) and Chugaikasei Co., Ltd. (Fukushima, Japan), respectively. Dodecane, 1,2-dichloroethane, Span 80, 4, 4'-bisphenol, octafluoro-4, 4'-biphenol, acetophenone, 2', 3', 4', 5', 6'-pentafluoroacetophenone, and trans-cinnamic acid were all received from Tokyo Chemical Industry Co., Ltd. (Tokyo, Japan). Trans-2,3,4,5,6-pentafluorocinnamic acid was purchased from Synquest Laboratories (FL, USA). Fluoroalkyl end-capped vinyltrimethoxysilane oligomer $\left[\mathrm{R}_{\mathrm{F}}-\left(\mathrm{CH}_{2}-\mathrm{CHSi}(\mathrm{OMe})_{3}\right)_{n}-\mathrm{R}_{\mathrm{F}}\right.$ : the mixture of dimer and trimer; $\left.\mathrm{R}_{\mathrm{F}}=\mathrm{CF}\left(\mathrm{CF}_{3}\right) \mathrm{OC}_{3} \mathrm{~F}_{7}\left(\mathrm{R}_{\mathrm{F}}-(\mathrm{VM})_{n}-\mathrm{R}_{\mathrm{F}}\right) ; \mathrm{Mn}=780\right]$ was synthesized by reaction of fluoroalkanoyl peroxide with the corresponding monomer according to our previously reported method [27]. Solid-phase extraction cartridge connected with the polyethylene frit [Type Mini $(0.1 \mathrm{~mL})$ ] was supplied by Tomoe-Works Co., Ltd. (Amagasaki, Japan).

\subsection{Preparation of Fluoroalkyl End-Capped Vinyltrimethoxysilane Oligomer/Ottawa Sand (OS) Composites $\left[\mathrm{R}_{\mathrm{F}}-\left(\mathrm{VM}-\mathrm{SiO}_{3 / 2}\right)_{n}-\mathrm{R}_{\mathrm{F}} / \mathrm{OS}\right]$}

A typical procedure for the facile preparation of $\mathrm{R}_{\mathrm{F}}-\left(\mathrm{VM}-\mathrm{SiO}_{3 / 2}\right)_{n}-\mathrm{R}_{\mathrm{F}} / \mathrm{OS}$ composites is as follows: To methanol solution $(5 \mathrm{~mL})$ containing fluoroalkyl endcapped vinyltrimethoxysilane oligomer $\left[\mathrm{R}_{\mathrm{F}}-(\mathrm{VM})_{n}-\mathrm{R}_{\mathrm{F}}\right](50 \mathrm{mg})$ was added OS particles $(150 \mathrm{mg})$. The mixture was stirred with a magnetic stirring bar at room temperature for $10 \mathrm{~min}$. $25 \%$ aqueous ammonia solution $(2.0 \mathrm{ml})$ was added to the methanol solution, and was successively stirred at room temperature for 5 hrs. After the solvent was evaporated off, the obtained product was dried under vacuum at $50^{\circ} \mathrm{C}$ for 1 day to produce the expected fluorinated composite white colored powders (166 mg). Other composites were prepared under similar conditions. The results are demonstrated in Scheme 1 and Table $1 . \mathrm{R}_{\mathrm{F}}-\left(\mathrm{VM}-\mathrm{SiO}_{3 / 2}\right)_{n^{-}}$ $\mathrm{R}_{\mathrm{F}} / \mu-\mathrm{SiO}_{2}$ composites were also prepared by using micro-sized silica particles ( $\mu$-SiO $\mathrm{Siv}_{2}$ average particle size: $14 \mu \mathrm{m}$ ) under similar conditions, for comparison (see Scheme 2).

\subsection{Contact Angle Measurements of Dodecane and Water on the $\mathbf{R}_{\mathrm{F}}-\left(\mathrm{VM}-\mathrm{SiO}_{3 / 2}\right)_{n}-\mathbf{R}_{\mathrm{F}} /$ OS composite Powders Surface}

The $\mathrm{R}_{\mathrm{F}}-\left(\mathrm{VM}-\mathrm{SiO}_{3 / 2}\right)_{n}-\mathrm{R}_{\mathrm{F}} / \mathrm{OS}$ composite powders $(2 \mathrm{mg})$ were added into the aluminum crucible (volume: $40 \mu \mathrm{L}$ ). The contact angles of dodecane and water were measured by the deposit of each droplet $(2 \mu \mathrm{L})$ on the composite powders surface 
at room temperature. The contact angle measurements of dodecane and water on the other composite powders were conducted under the similar conditions.

\subsection{Preparation of the Surfactant-Stabilized Water-in-0il (1,2-Dichloroethane) Emulsion}

The surfactant (span $80: 30 \mathrm{mg}$ ) was added into the mixture of water $(0.05 \mathrm{~mL})$ and 1,2-dichloroethane $(5.0 \mathrm{~mL})$. The expected white-colored W/O emulsion was easily prepared through the ultrasonic irradiation of the obtained mixture for 5 min at room temperature.

\subsection{Removal of 2', 3', 4', 5', 6'-Pentafluoroacetophenone (PFAP) in Aqueous Methanol Solution by Using the $\mathbf{R}_{\mathrm{F}}-\left(\mathrm{CH}_{2} \mathrm{CHSiO}_{3 / 2}\right)_{n}-\mathrm{R}_{\mathrm{F}} /$ OS Composite Powders}

Solid-phase extraction cartridge connected with the polyethylene frit packed with the $\mathrm{R}_{\mathrm{F}}-\left(\mathrm{CH}_{2} \mathrm{CHSiO}_{3 / 2}\right)_{n}-\mathrm{R}_{\mathrm{F}} / \mathrm{OS}$ composite powders $(10 \mathrm{mg}$ : Run 1 in Table 1) was used for the removal of PFAP. $5 \mathrm{~mL}$ of aqueous methanol solution [ $\mathrm{H}_{2} \mathrm{O} / \mathrm{MeOH}: 94 / 6$ ( $\left.\left.\mathrm{vol} / \mathrm{vol}\right)\right]$ containing PFAP $\left(30 \mathrm{mg} / \mathrm{dm}^{3}\right)$ was applied to the cartridge, and the obtained eluent was analyzed by UV-vis spectra measurements to detect the residual PFAP. The residual amounts of other organic compounds were also analyzed under similar conditions. The results are summarized following.

\section{Results and Discussion}

Fluoroalkyl end-capped vinyltrimethoxysilane oligomer $\left[\mathrm{R}_{\mathrm{F}}-(\mathrm{VM})_{n}-\mathrm{R}_{\mathrm{F}}\right]$ was found to undergo the sol-gel reaction in the presence of Ottawa sand (OS) particles under alkaline conditions at room temperature, providing the corresponding fluorinated oligomeric silica/OS composites. The results are depicted in Scheme 1 and Table 1.

Scheme 1 and Table 1 show that the expected composites can be easily obtained through the sol-gel reaction under alkaline conditions in good isolated yields: $64 \%-97 \%$. The content of each oligomer in the composites in Table 1 was determined by using the thermogravimetric analyses (TGA), in which the weight loss of the composites was measured by raising the temperature around $800^{\circ} \mathrm{C}$ at a $10^{\circ} \mathrm{C} / \mathrm{min}$ heating rate under air atmospheric conditions, and the results are also demonstrated in Table 1. TGA curves of some composites in Table 1 are illustrated in Figure 1. The pristine OS powders and the $\mathrm{R}_{\mathrm{F}}-\left(\mathrm{VM}-\mathrm{SiO}_{3 / 2}\right)_{n}-\mathrm{R}_{\mathrm{F}}$ oligomeric nanoparticles [28], which were prepared by the sol-gel reaction of the corresponding oligomer under alkaline conditions, are also shown in Figure 1, for comparison.

As shown in Table 1 and Figure 1, the contents of oligomers were estimated

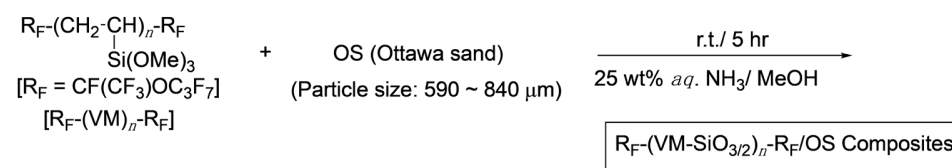

Scheme 1. Preparation of $\mathrm{R}_{\mathrm{F}}-\left(\mathrm{VM}-\mathrm{SiO}_{3 / 2}\right)_{n}-\mathrm{R}_{\mathrm{F}} / \mathrm{OS}$ composites. 
Table 1. Preparation of $\mathrm{R}_{\mathrm{F}}-\left(\mathrm{VM}-\mathrm{SiO}_{3 / 2}\right)_{n}-\mathrm{R}_{\mathrm{F}} / \mathrm{OS}$ composites.

\begin{tabular}{ccccc}
\hline Run & $\mathrm{R}_{\mathrm{F}}-(\mathrm{VM})_{n}-\mathrm{R}_{\mathrm{F}}(\mathrm{mg})$ & OS (mg) & Yield $(\%)^{*}$ & $\begin{array}{c}\text { Content of oligomer } \\
\text { in the composites }(\%)^{* *}\end{array}$ \\
\hline 1 & 50 & 10 & 64 & 66 \\
2 & 50 & 50 & 82 & 39 \\
3 & 50 & 75 & 84 & 44 \\
4 & 50 & 100 & 89 & 39 \\
5 & 50 & 150 & 83 & 12 \\
6 & 50 & 200 & 93 & 26 \\
7 & 50 & 250 & 94 & 24 \\
8 & 50 & 300 & 93 & 9 \\
9 & 50 & 400 & 95 & 5 \\
10 & 50 & 500 & 95 & 18 \\
11 & 50 & 600 & 97 & 7 \\
12 & 50 & 700 & 97 & 5 \\
\hline
\end{tabular}

${ }^{*}$ Yield was based on oligomer and OS; ${ }^{*}$ Content of oligomer in each composite was determined by using the weight loss value at $800^{\circ} \mathrm{C}$ of the composites and the $\mathrm{R}_{\mathrm{F}}(\mathrm{VM}$ $\left.\mathrm{SiO}_{3 / 2}\right)_{n}-\mathrm{R}_{\mathrm{F}}$ oligomeric nanoparticles

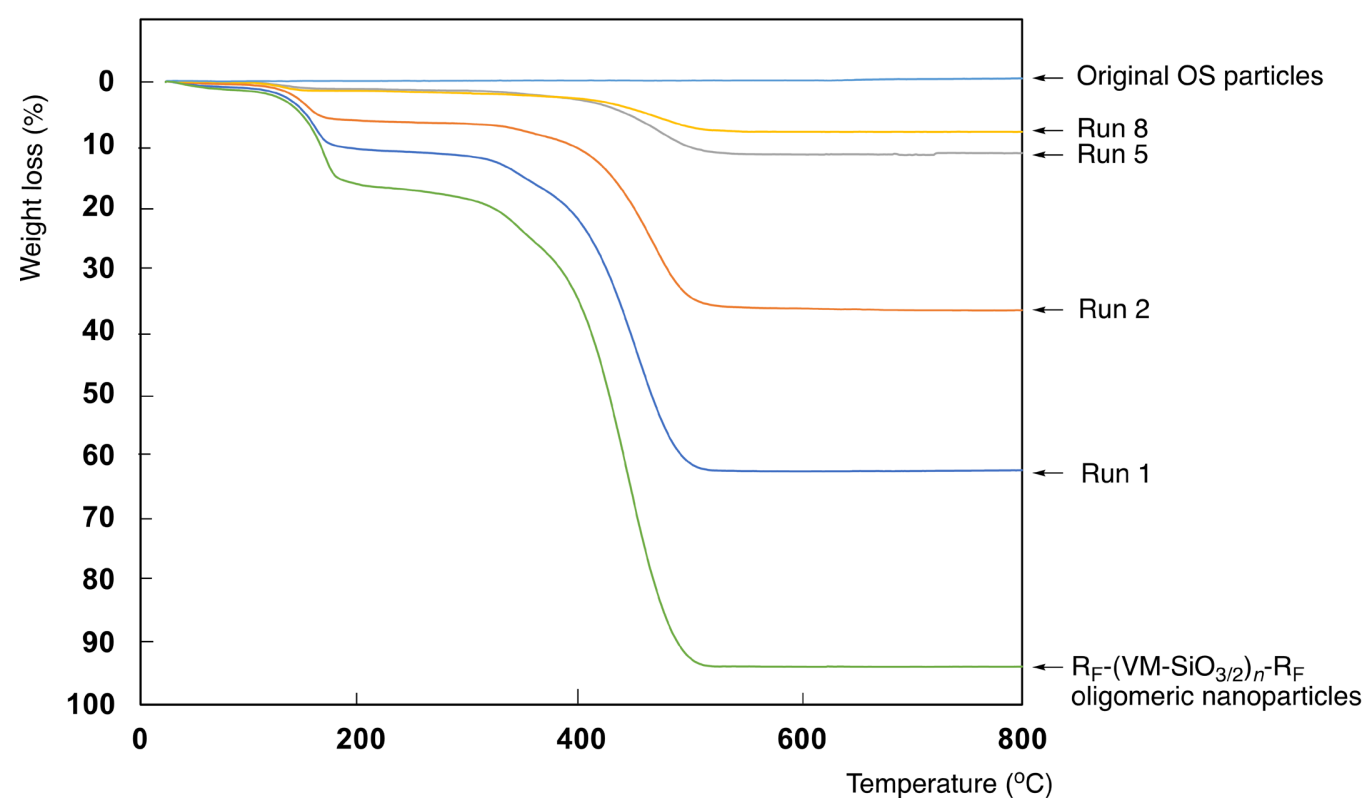

Figure 1. Thermogravimetric analysis (TGA) of the $\mathrm{R}_{\mathrm{F}}\left(\mathrm{VM}-\mathrm{SiO}_{3 / 2}\right)_{n}-\mathrm{R}_{\mathrm{F}} / \mathrm{OS}$ composites (Runs 1, 2, 5 and 8 in $\mathrm{Ta}$ ble 1), original OS particles, and $\mathrm{R}_{\mathrm{F}}-\left(\mathrm{VM}-\mathrm{SiO}_{3 / 2}\right)_{n}-\mathrm{R}_{\mathrm{F}}$ oligomeric nanoparticles, which were prepared under the similar sol-gel reaction of the corresponding oligomer to that of Scheme 1.

to be $5 \%-66 \%$ by the use of the TGA measurements. The contents of oligomers in the composites were found to decrease from $66 \%$ to $5 \%$ or $7 \%$ with increasing the feed amounts of OS particles from 10 to 500 or $700 \mathrm{mg}$, suggesting that the 
sol-gel reactions in Scheme 1 should proceed smoothly to provide the expected composites.

FE-SEM (Field Emission Scanning Electron Micrograph) photographs of the $\mathrm{R}_{\mathrm{F}}-\left(\mathrm{VM}-\mathrm{SiO}_{3 / 2}\right)_{n}-\mathrm{R}_{\mathrm{F}} / \mathrm{OS}$ composites (Run 5 in Table 1 ) have been recorded to clarify the formation of the composites, and the results are shown in Figure 2. FE-SEM picture of the pristine OS particles has been also illustrated in Figure 2, for comparison.

We can observe not only the uniformly coated-fluorinated oligomeric nanoparticles $\left[\mathrm{R}_{\mathrm{F}}-\left(\mathrm{VM}-\mathrm{SiO}_{3 / 2}\right)_{n}-\mathrm{R}_{\mathrm{F}}\right]$ on the OS particle surface but also the dispersed oligomeric nanoparticles near the OS particles (see Figure 2(B)). EDX (Energy Dispersive X-Ray) analyses measurements of the $\mathrm{R}_{\mathrm{F}}-\left(\mathrm{VM}-\mathrm{SiO}_{3 / 2}\right)_{n}-\mathrm{R}_{\mathrm{F}} / \mathrm{OS}$ composites (Run 5 in Table 1) also reveal that the atomic contents of silicon, fluorine and carbon are as follows (see Table 2).

The decrease of the contents of silicon from $44 \%$ to $14 \%$ in the composites, and the contents of fluorine (35\%) and carbon (30\%) indicate the presence of the fluorinated oligomer in the composites. The presence of $\mathrm{Al}$ in the original $\mathrm{OS}$ particles is due to the impurities in the particles. EDX mapping micrographs on the $\mathrm{R}_{\mathrm{F}}-\left(\mathrm{VM}-\mathrm{SiO}_{3 / 2}\right)_{n}-\mathrm{R}_{\mathrm{F}} / \mathrm{OS}$ composites (Run 5 in Table 1 ) and the pristine OS particles show that fluorine (blue-colored area) and carbon (red-colored area) related to the fluorinated oligomer are uniformly dispersed on the OS particle surface and around OS particles (see Figure 3).

We tried to study on the surface wettability of the $\mathrm{R}_{\mathrm{F}}-\left(\mathrm{VM}-\mathrm{SiO}_{3 / 2}\right)_{n}-\mathrm{R}_{\mathrm{F}} / \mathrm{OS}$

(A)

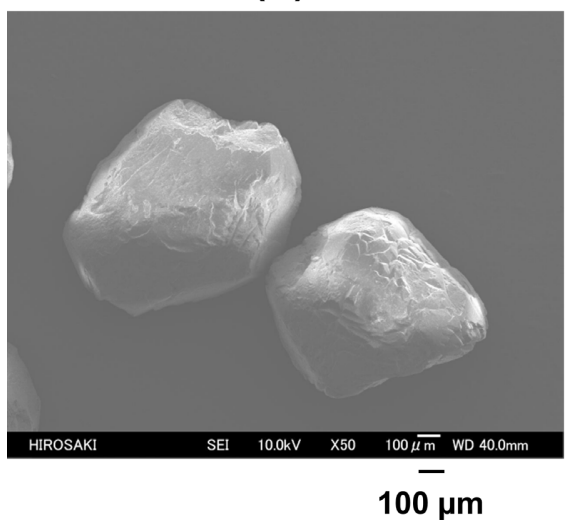

(B)

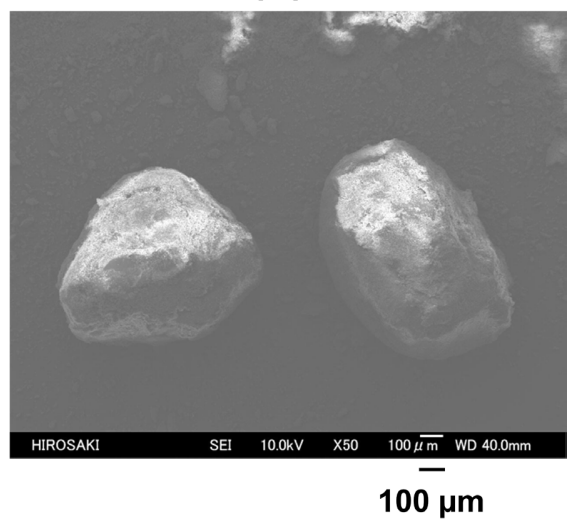

Figure 2. FE-SEM images of the $\mathrm{R}_{\mathrm{F}}-\left(\mathrm{VM}-\mathrm{SiO}_{3 / 2}\right)_{n}-\mathrm{R}_{\mathrm{F}} / \mathrm{OS}$ composites powders (Run 5 in Table 1) (B) and the pristine OS particles (A).

Table 2. The atomic contents of silicon, fluorine and carbon of the $\mathrm{R}_{\mathrm{F}}-\left(\mathrm{VM}-\mathrm{SiO}_{3 / 2}\right)_{n}-\mathrm{R}_{\mathrm{F}} / \mathrm{OS}$ composites (Run 5 in Table 1), and the pristine OS particles.

\begin{tabular}{ccccc}
\hline & \multicolumn{5}{c}{ Atomic contents (atm, \%) } \\
\cline { 2 - 5 } & $\mathrm{Si}$ & $\mathrm{F}$ & $\mathrm{C}$ & $\mathrm{Al}$ \\
\hline Pristine OS particles & 44 & 0.0 & 0.0 & 1.0 \\
$\mathrm{R}_{\mathrm{F}}-\left(\mathrm{VM}-\mathrm{SiO}_{3 / 2}\right)_{n}-\mathrm{R}_{\mathrm{F}} / \mathrm{OS}$ composites & 14 & 35 & 30 & 0.0 \\
\hline
\end{tabular}


(A)

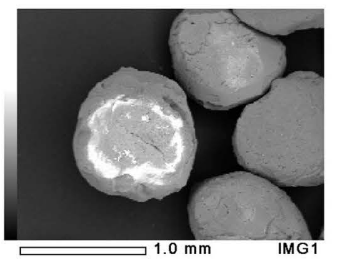

(C)

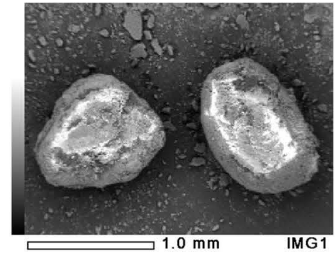

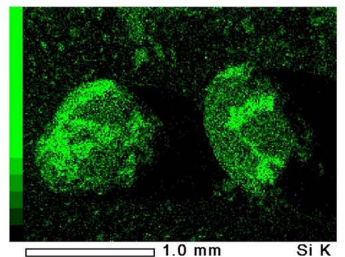

Silicon
(B)

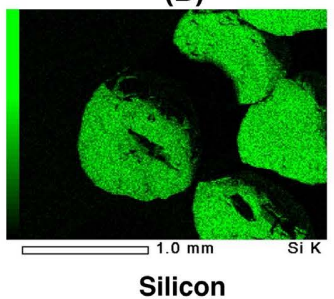

(D)

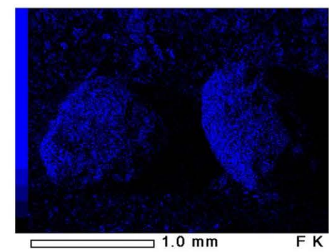

Fluorine
(F)

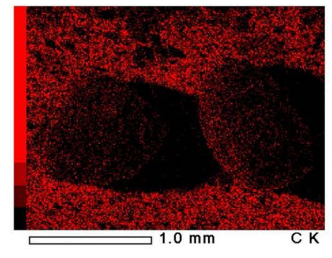

Carbon

Figure 3. EDX (Energy Dispersive X-ray) mapping micrographys of silicon (B) of the pristine OS particles (A), and silicon (D), fluorine (E) and carbon (F) of the $\mathrm{R}_{\mathrm{F}}-\left(\mathrm{VM}-\mathrm{SiO}_{3 / 2}\right)_{n}-\mathrm{R}_{\mathrm{F}} / \mathrm{OS}$ composites powders (Run 5 in Table 1) (C).

composites powders: Runs 1-12 in Table 1 and the pristine OS particles through the dodecane and water contact angle measurements. The results are revealed as followings:

\begin{tabular}{ccc}
\hline & \multicolumn{2}{c}{ Contact angle value (Degree) } \\
\cline { 2 - 3 } & Dodecane & Water \\
\hline Pristine OS particles & 0 & 0 \\
$\mathrm{R}_{\mathrm{F}}-\left(\mathrm{VM}-\mathrm{SiO}_{3 / 2}\right)_{n}-\mathrm{R}_{\mathrm{F}} / \mathrm{OS}$ composites (Runs 1 - 12) & 0 & 180 \\
\hline
\end{tabular}

Dodecane and water contact angle values of the pristine OS particles are 0 degree, respectively; however, each $\mathrm{R}_{\mathrm{F}}-\left(\mathrm{VM}-\mathrm{SiO}_{3 / 2}\right)_{n}-\mathrm{R}_{\mathrm{F}} / \mathrm{OS}$ composite powder (Runs $1 \sim 12$ in Table 1) can exhibit a superoleophilic/superhydrophobic characteristic on its surface, because a dodecane droplet $(2 \mu \mathrm{L})$ can be easily adsorbed on the composite surface to exhibit the dodecane contact angle value: 0 degree, and water droplet $(2 \mu \mathrm{L})$ cannot be placed on the surface even after the pull-up process of the needlepoint from the surface during the water contact angle measurements owing to the superhydrophobic property in each case. We define the water contact angle value on its surface as 180 degrees in this case. In fact, as shown in Figure 4(A), we can easily observe the sedimentation of the original OS particle powders into water; however, our present $\mathrm{R}_{\mathrm{F}}-\left(\mathrm{VM}-\mathrm{SiO}_{3 / 2}\right)_{n}-\mathrm{R}_{\mathrm{F}} / \mathrm{OS}$ composite powders can possess a perfect repellent ability toward water, floating on the water interface due to the superhydrophobicity related to the composite powders (see Figure 4(B)).

In this way, it was clarified that the present $\mathrm{R}_{\mathrm{F}}-\left(\mathrm{VM}-\mathrm{SiO}_{3 / 2}\right)_{n}-\mathrm{R}_{\mathrm{F}} / \mathrm{OS}$ composite powders can provide a superoleophilic/superhydrophobic property on their sur- 
face. Thus, it is strongly expected that these composite powders should be applicable to the separation of the mixture of oil and water. Because, superoleophilic surface can provide a good affinity toward organic oils. Thus, superoleophilic/superhydrophobic surface should simultaneously repel water and adsorb oils effectively. We tried to apply the $\mathrm{R}_{\mathrm{F}}-\left(\mathrm{VM}-\mathrm{SiO}_{3 / 2}\right)_{n}-\mathrm{R}_{\mathrm{F}} / \mathrm{OS}$ composite powders (100 mg: Run 2 in Table 1) as the packing material for column chromatography to separate the mixture of water $(3 \mathrm{~mL})$ and 1,2-dichloroethane $(3 \mathrm{~mL})$, and the results are shown in Figure 5. We also tried to apply the $\mathrm{R}_{\mathrm{F}}-\left(\mathrm{VM}-\mathrm{SiO}_{3 / 2}\right)_{n}-\mathrm{R}_{\mathrm{F}} /$ micro-sized controlled silica gel composites $\left[\mathrm{R}_{\mathrm{F}}-\left(\mathrm{VM}-\mathrm{SiO}_{3 / 2}\right)_{n}-\mathrm{R}_{\mathrm{F}} / \mu-\mathrm{SiO}_{2}\right]$ powders, which were prepared under the similar conditions to those of Scheme 1 and Table 1 (see Scheme 2), as the packing material (100 mg) to separate the mixture of water and 1,2-dichloroethane. Because, the $\mathrm{R}_{\mathrm{F}}-\left(\mathrm{VM}-\mathrm{SiO}_{3 / 2}\right)_{n}-\mathrm{R}_{\mathrm{F}} / \mu-\mathrm{SiO}_{2}$ composites powders were found to exhibit the same surface wettability to that of the $R_{F}-(V M-$ $\left.\mathrm{SiO}_{3 / 2}\right)_{n}-\mathrm{R}_{\mathrm{F}} / \mathrm{OS}$ composites powders. The results are also shown in Figure $5(\mathrm{C})$, for comparison.

As shown in Figure 5(B), we cannot separate the mixture of water and bluecolored 1,2-dichloroethane (DE) by using the pristine OS particles and $\mu-\mathrm{SiO}_{2}$

(A)

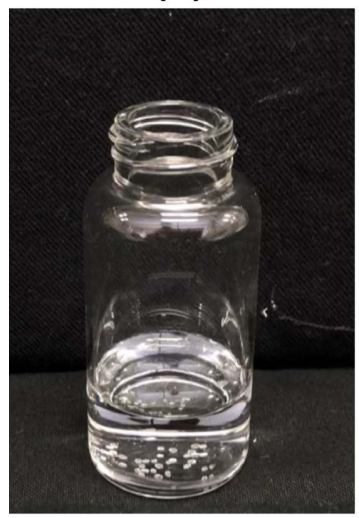

(B)

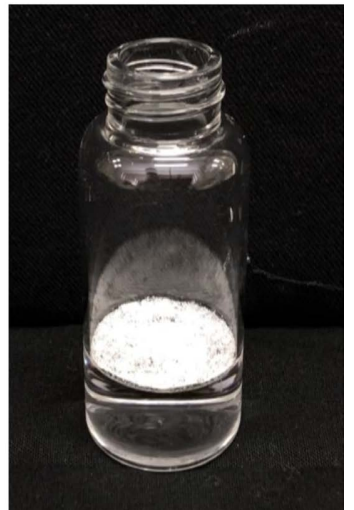

Figure 4. Photograph of the pristine OS powders in water: $(\mathrm{A})$ and the $\mathrm{R}_{\mathrm{F}}-\left(\mathrm{VM}-\mathrm{SiO}_{3 / 2}\right)_{n^{-}}$ $\mathrm{R}_{\mathrm{F}} / \mathrm{OS}$ composites powders (Run 2 in Table 1 ) in water: (B).

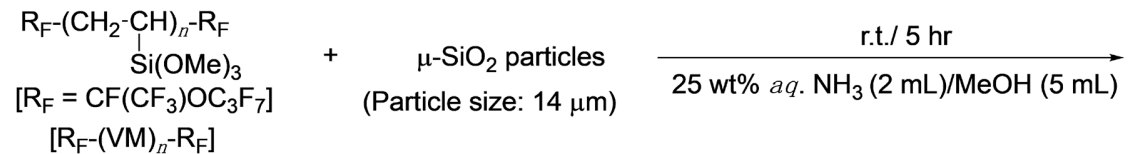

$\mathrm{R}_{\mathrm{F}}-\left(\mathrm{VM}-\mathrm{SiO}_{3 / 2}\right)_{n}-\mathrm{R}_{\mathrm{F}} / \mu-\mathrm{SiO}_{2}$ Composites

$\mathrm{R}_{\mathrm{F}}-(\mathrm{VM})_{n}-\mathrm{R}_{\mathrm{F}} \mu-\mathrm{SiO}_{2}$ particles Yield $(\%)^{*}$ Size of the composites $(\mu \mathrm{m})^{* *}$ Content of oligomer in the composites $(\%)^{\star * *}$

\begin{tabular}{llllll}
\hline Run 1 & 50 & 10 & 73 & $8.1 \pm 0.3$ & 77 \\
Run 2 & 50 & 50 & 67 & $9.5 \pm 0.3$ & 50 \\
\hline
\end{tabular}

*Yield was based on the used oligomer and $\mu-\mathrm{SiO}_{2}$ particles

**Determined by laser diffraction analysis measuremnts in methanol

${ }^{* * *}$ Content of oligomer was estimated by the weight loss value at $800^{\circ} \mathrm{C}$ of the composites by TGA measurements

Scheme 2. Preparation of $\mathrm{R}_{\mathrm{F}}-\left(\mathrm{VM}-\mathrm{SiO}_{3 / 2}\right)_{n}-\mathrm{R}_{\mathrm{F}} / \mu-\mathrm{SiO}_{2}$ composites. 


\section{Blue-colored aqueous solution (water was colored with Acid Blue 112)}

1,2-Dichloroethane
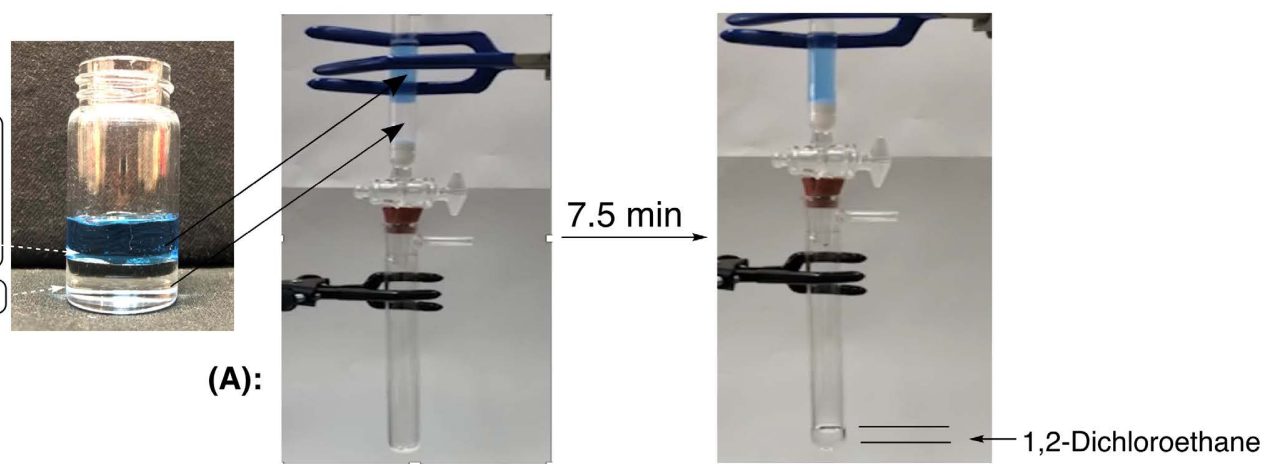

(B):
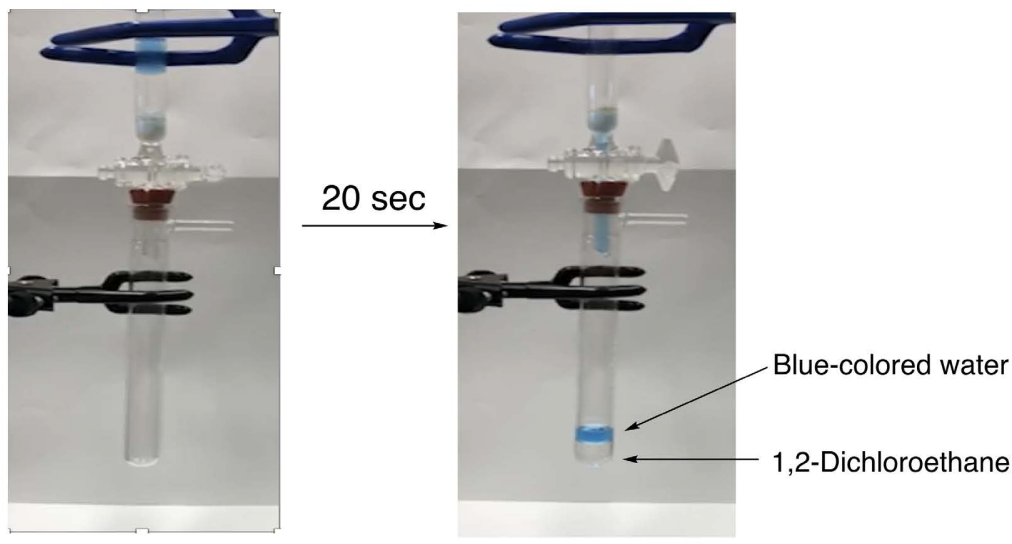

(C):
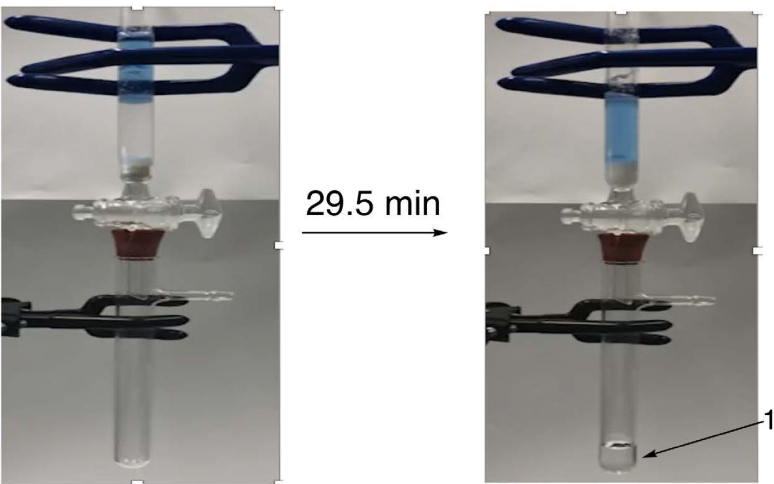

,2-Dichloroethane

Figure 5. Separation of the mixture of blue-colored water and 1,2-dichloroethane by using the $\mathrm{R}_{\mathrm{F}}-\left(\mathrm{VM}-\mathrm{SiO}_{3 / 2}\right)_{n}-\mathrm{R}_{\mathrm{F}} / \mathrm{OS}$ composites powders (100 mg: Run 2 in Table 1): (A), pristine OS particles (100 mg): (B), and R $\mathrm{F}_{\mathrm{F}}\left(\mathrm{VM}-\mathrm{SiO}_{3 / 2}\right)_{n}-\mathrm{R}_{\mathrm{F}} / \mu-\mathrm{SiO}_{2}$ composites powders (100 mg: Run 2 in Scheme 2): (C) as the packing materials, respectively.

particles (date not shown), although the rapid filtration behavior (20 sec) was observed, as well as the use of the original $\mu-\mathrm{SiO}_{2}$ particles (data not shown). On the other hand, we can smoothly isolate the colorless oil (DE) in $7.5 \mathrm{~min}$ by using the $\mathrm{R}_{\mathrm{F}}-\left(\mathrm{VM}-\mathrm{SiO}_{3 / 2}\right)_{n}-\mathrm{R}_{\mathrm{F}} / \mathrm{OS}$ composites powders (Run 2 in Table 1 ) as the packing material (see Figure 5(A)). In contrast, it was demonstrated that the $\mathrm{R}_{\mathrm{F}}-\left(\mathrm{VM}-\mathrm{SiO}_{3 / 2}\right)_{n}-\mathrm{R}_{\mathrm{F}} / \mu-\mathrm{SiO}_{2}$ composites powders (Run 2 in Scheme 2 ) requires the longer time from 7.5 to 29.5 min to isolate the transparent colorless DE un- 
der similar conditions (see Figure 5(C)). This efficient and higher separation behavior in the $\mathrm{R}_{\mathrm{F}}-\left(\mathrm{VM}-\mathrm{SiO}_{3 / 2}\right)_{n}-\mathrm{R}_{\mathrm{F}} / \mathrm{OS}$ composites powders is due to the larger particle size $(\sim 840 \mu \mathrm{m})$ of OS particles than that $(14 \mu \mathrm{m})$ of the $\mu-\mathrm{SiO}_{2}$ particles in the fluorinated oligomeric composites.

In addition to the separation of the mixture of water and DE, we tried to separate the W/O (oil: DE) emulsion by the use of the $\mathrm{R}_{\mathrm{F}}-\left(\mathrm{VM}-\mathrm{SiO}_{3 / 2}\right)_{n}-\mathrm{R}_{\mathrm{F}} / \mathrm{OS}$ composites powders (Run 2 in Table 1 ) as the packing material, and the results are shown in Figure 6.

As shown in Figure 6, we can isolate the transparent colorless oil (DE) by using the $\mathrm{R}_{\mathrm{F}}-\left(\mathrm{VM}-\mathrm{SiO}_{3 / 2}\right)_{n}-\mathrm{R}_{\mathrm{F}} / \mathrm{OS}$ composites powders (Run 2 in Table 1) as the packing material. Optical micrograph also revealed that the water droplet cannot be detected in the isolated oil at all, although water droplets can be easily observed in the original W/O emulsion as shown in Table 3. Table 3 also shows that the colorless oils were quantitatively isolated in recovery rate from $81 \%-85 \%$ even after the use of the $\mathrm{O} / \mathrm{W}$ emulsions four times under similar conditions.

As mentioned above, particular attention has been devoted to the development of practical technology for removal of organic micropollutants, especially

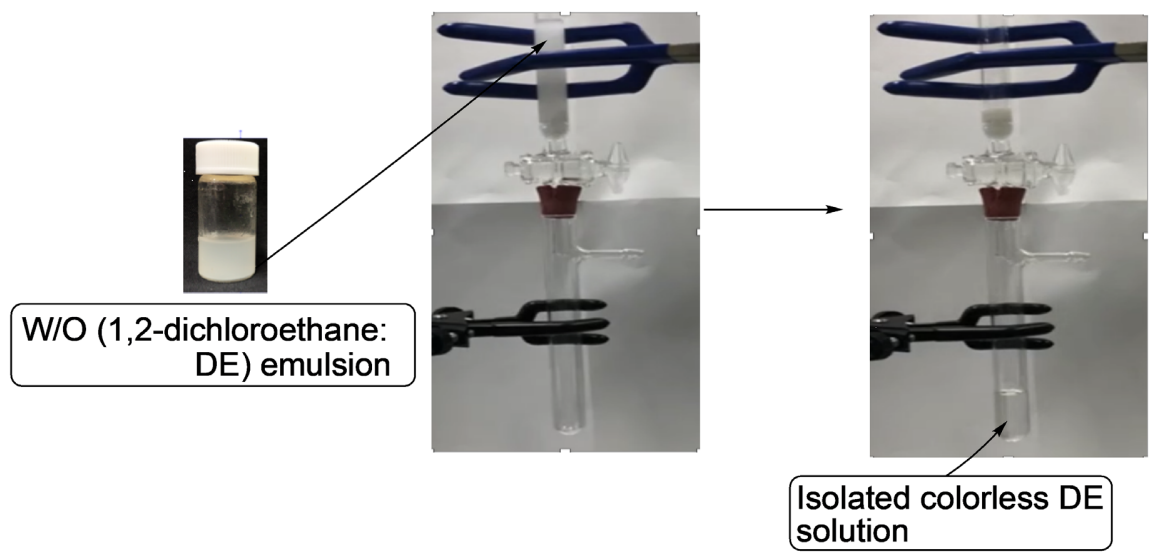

Figure 6. Separation of W/O (1,2-dichloroethane: $\mathrm{DE})$ by using the $\mathrm{R}_{\mathrm{F}}-\left(\mathrm{VM}-\mathrm{SiO}_{3 / 2}\right)_{n}-\mathrm{R}_{\mathrm{F}} / \mathrm{OS}$ composites powders (100 mg: Run 2 in Table 1 ) as the packing material.

Table 3. Recovered rate and optical microscopy images of the separated oil from the W/O(oil: DE) emulsion by using the $\mathrm{R}_{\mathrm{F}}-\left(\mathrm{VM}-\mathrm{SiO}_{3 / 2}\right)_{n}-\mathrm{R}_{\mathrm{F}} / \mathrm{OS}$ composites powders (Run 2 in Table 1).

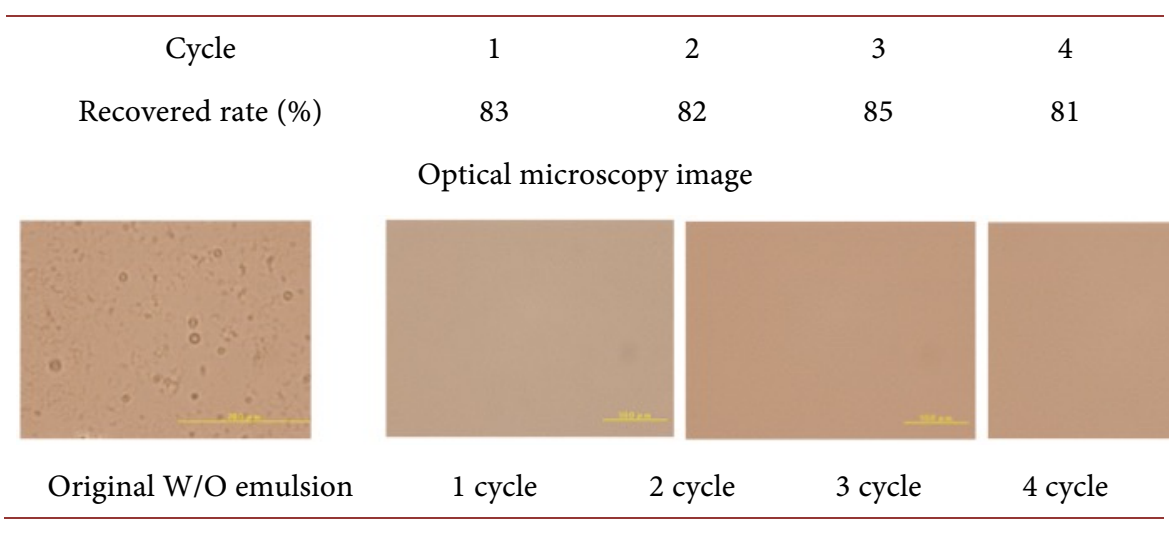


fluorinated organic micropollutants from industrial wastewater [10]-[15]. Our present $\mathrm{R}_{\mathrm{F}}-\left(\mathrm{VM}-\mathrm{SiO}_{3 / 2}\right)_{n}-\mathrm{R}_{\mathrm{F}} / \mathrm{OS}$ composites are expected to enhance the removal ability toward the fluorinated organic compounds through the fluorophilic-fluorophilic interaction between the fluorinated moieties in organic molecules and the fluoroalkyl units in the composites. Superoleophilic/superhydrophobic property in the present fluorinated composites is also expected to enhance the removal ability of fluorinated compounds from aqueous solution through the effective oleophilic-oleophilic interaction between the organic molecules and the composites in aqueous solution with the superhydrophobicity on the composites. We herein tried to study on the removal ability of some fluorinated aromatic molecules including the corresponding non-fluorinated ones from aqueous methanol solutions by the use of the $\mathrm{R}_{\mathrm{F}}-\left(\mathrm{VM}-\mathrm{SiO}_{3 / 2}\right)_{n}-\mathrm{R}_{\mathrm{F}} / \mathrm{OS}$ composites powders (Run 1 in Table 1). The Schematic outline of the removal process is illustrated in Figure 7. We have also studied on the removal ability of the above indicated compounds from aqueous methanol solutions by using the $\mathrm{R}_{\mathrm{F}}-\left(\mathrm{VM}-\mathrm{SiO}_{3 / 2}\right)_{n}-\mathrm{R}_{\mathrm{F}} / \mu-\mathrm{SiO}_{2}$ composites powders (Run 1 in Scheme 2) under similar conditions, for comparison. The structures and concentrations $\left(\mathrm{mg} / \mathrm{dm}^{3}\right)$ of the used fluorinated and non-fluorinated aromatic molecules are demonstrated in Table 4, and the removal ratios of these compounds are summarized in Table 5.

As shown in Table 5, the pristine OS particles and the $\mu-\mathrm{SiO}_{2}$ particles exhibited the extremely poor removal ability for the fluorinated and non-fluorinated organic molecules; however, the $\mathrm{R}_{\mathrm{F}}-\left(\mathrm{VM}-\mathrm{SiO}_{3 / 2}\right)_{n}-\mathrm{R}_{\mathrm{F}} / \mathrm{OS}$ composites can give a higher removal ability toward the fluorinated organic molecules such as OFBP,

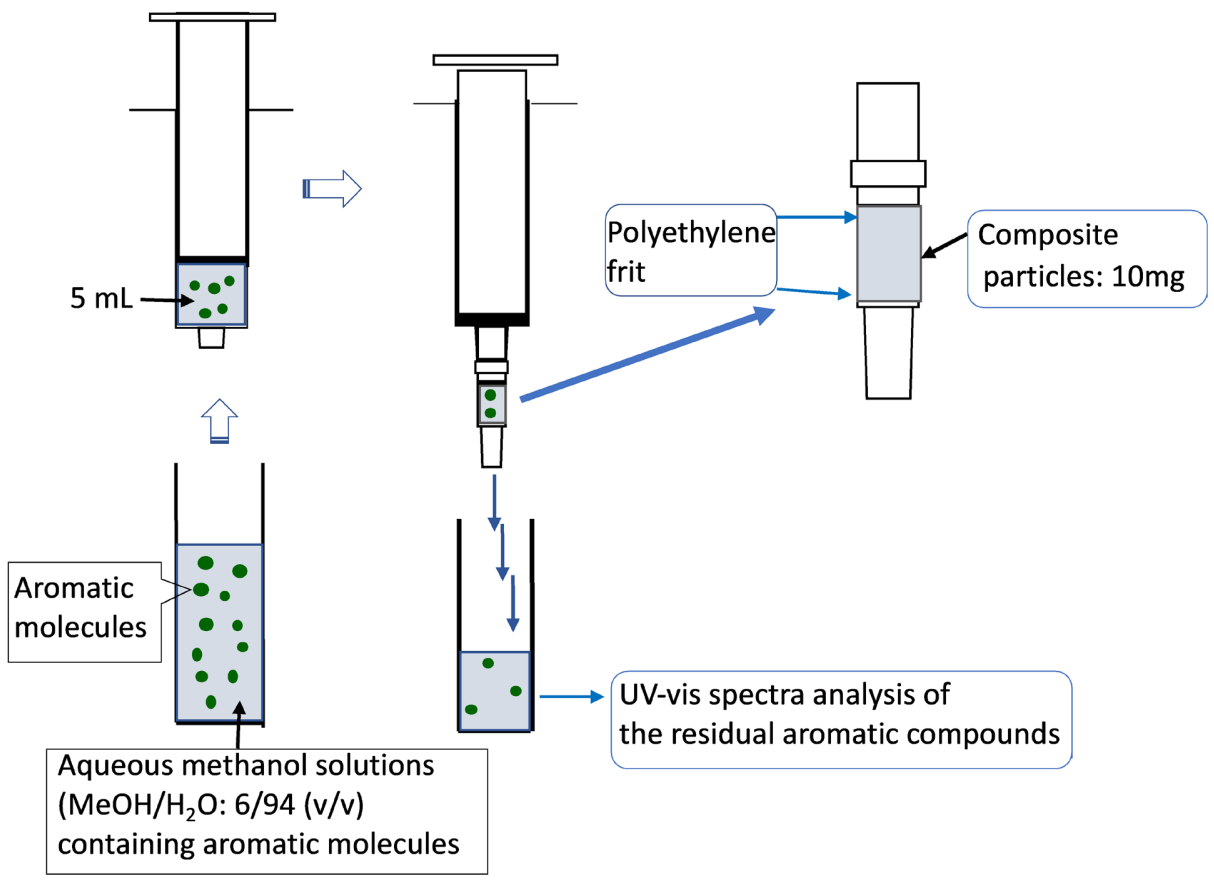

Figure 7. Schematic outline for the analysis of the removal ratio of aromatic molecules by using the $\mathrm{R}_{\mathrm{F}}-\left(\mathrm{VM}-\mathrm{SiO}_{3 / 2}\right)_{n}-\mathrm{R}_{\mathrm{F}} / \mathrm{OS}$ composites powders (10 mg: Run 1 in Table 1$)$ and the $\mathrm{R}_{\mathrm{F}}-\left(\mathrm{VM}-\mathrm{SiO}_{3 / 2}\right)_{n}-\mathrm{R}_{\mathrm{F}} / \mu-\mathrm{SiO}_{2}$ composites powders (10 mg: Run 1 in Scheme 2 ). 
Table 4. Structures and the concentrations of the used aromatic compounds for the analysis of the removal ratios.

(Bcetophenone [AP]

Table 5. Removal ratio (\%) of aromatic compounds by using the $\mathrm{R}_{\mathrm{F}}-\left(\mathrm{VM}-\mathrm{SiO}_{3 / 2}\right)_{n}-\mathrm{R}_{\mathrm{F}} / \mathrm{OS}$ composites powders (Run 1 in Table 1 ), pristine OS particles, the $\mathrm{R}_{\mathrm{F}}-\left(\mathrm{VM}-\mathrm{SiO}_{3 / 2}\right)_{n}-\mathrm{R}_{\mathrm{F}} /$ $\mu-\mathrm{SiO}_{2}$ composites powders (Run 1 in Scheme 2 ), and pristine $\mu-\mathrm{SiO}_{2}$ particles.

\begin{tabular}{ccccccc}
\hline \multirow{2}{*}{ Composite } & \multicolumn{6}{c}{ Removal ratio (\%) of aromatic compounds } \\
\cline { 2 - 7 } & BP-4,4 & OFBP & AP & PFAP & CA & PFCA \\
\hline $\mathrm{R}_{\mathrm{F}-}\left(\mathrm{VM}-\mathrm{SiO}_{3 / 2}\right)_{n}-\mathrm{R}_{\mathrm{F}} / \mathrm{OS}$ composites & 0 & 26 & 46 & 86 & 1 & 19 \\
$\mathrm{OS}$ particles & 1 & 0 & 1 & 12 & 1 & 12 \\
$\mathrm{R}_{\mathrm{F}}-\left(\mathrm{VM}-\mathrm{SiO}_{3 / 2}\right)_{n}-\mathrm{R}_{\mathrm{F}} / \mu-\mathrm{SiO}_{2}$ composites & 1 & 0 & 21 & 57 & 0 & 10 \\
$\mu-\mathrm{SiO}_{2}$ particles & 0 & 0 & 3 & 11 & 0 & 0 \\
\hline
\end{tabular}

PFAP and PFCA, compared to that of the corresponding non-fluorinated ones. Such higher removal ability toward the fluorinated molecules would be due to the effective fluorophilic-fluorophilic interaction between the fluorinated compounds and the fluorinated OS composites. In addition, it was verified that the $\mathrm{R}_{\mathrm{F}}-\left(\mathrm{VM}-\mathrm{SiO}_{3 / 2}\right)_{n}-\mathrm{R}_{\mathrm{F}} / \mathrm{OS}$ composites can exhibit the superior removal ability of organic molecules to that of the $\mathrm{R}_{\mathrm{F}}-\left(\mathrm{VM}-\mathrm{SiO}_{3 / 2}\right)_{n}-\mathrm{R}_{\mathrm{F}} / \mu-\mathrm{SiO}_{2}$ composites under similar conditions, indicating that the $\mathrm{R}_{\mathrm{F}}-\left(\mathrm{VM}-\mathrm{SiO}_{3 / 2}\right)_{n}-\mathrm{R}_{\mathrm{F}} / \mathrm{OS}$ composites would have more preferable cavities to adsorb these organic molecules in aqueous methanol solutions than that of the corresponding fluorinated $\mu-\mathrm{SiO}_{2}$ composites.

\section{Conclusion}

We have applied fluoroalkyl end-capped vinyltrimethoxysilane oligomer $\left[\mathrm{R}_{\mathrm{F}}-\right.$ $\left.(\mathrm{VM})_{n}-\mathrm{R}_{\mathrm{F}}\right]$ to the facile preparation of the fluorinated oligomeric silica/sand composites $\left[\mathrm{R}_{\mathrm{F}}-\left(\mathrm{VM}-\mathrm{SiO}_{3 / 2}\right)_{n}-\mathrm{R}_{\mathrm{F}} /\right.$ Ottawa sand (OS)] by the sol-gel reaction of the corresponding oligomer in the presence of micro-sized controlled OS particles 
(particle size: $590-840 \mu \mathrm{m})$ under alkaline conditions. $\mathrm{R}_{\mathrm{F}}-\left(\mathrm{VM}-\mathrm{SiO}_{3 / 2}\right)_{n}-\mathrm{R}_{\mathrm{F}} / \mathrm{OS}$ composites powders thus obtained were found to exhibit a superoleophilic/superhydrophobic characteristic on the particle surface, applying to the efficient and smooth separation of not only the mixture of oil and water but also the W/O emulsion. In addition, the $\mathrm{R}_{\mathrm{F}}-\left(\mathrm{VM}-\mathrm{SiO}_{3 / 2}\right)_{n}-\mathrm{R}_{\mathrm{F}} / \mu-\mathrm{SiO}_{2}$ composites, which were prepared under similar sol-gel conditions by using the micro-sized silica gel particles (average particle size: $14 \mu \mathrm{m}$ ), afforded the similar surface wettability to apply the separation of the mixture of oil and water. It was clarified that we can observe the higher efficient and smooth separation ability for the separation of oil/water by the use of the fluorinated OS composites, compared to the fluorinated $\mu-\mathrm{SiO}_{2}$ composites. Fluorinated OS composites were also found to exhibit a higher selective removal ability for the fluorinated organic molecules than that of the fluorinated $\mu-\mathrm{SiO}_{2}$ composites. From such a point of view, our present fluorinated OS composites will have high potential for the practical application to not only the separation of oil and water but also the selective removal of fluorinated aromatic compounds from wastewater.

\section{Funding}

This work was partially supported by a Grant-in-Aid for Scientific Research 19K05027 from the Ministry of Education, Science, Sports, and Culture, Japan.

\section{Conflicts of Interest}

The authors declare no conflicts of interest regarding the publication of this paper.

\section{References}

[1] Chu, Z.L., Feng, Y.J. and Seeger, S. (2014) Oil/Water Separation with Selective Superantiwetting/Superwetting Surface Materials. Angewandte Chemie International Edition, 54, 2328-2338. https://doi.org/10.1002/anie.201405785

[2] Kintish, E. (2010) An Audacious Decision in Crisis Gets Cautious Praise. Science, 329, 735-736. https://doi.org/10.1126/science.329.5993.735

[3] Gupta, R.K., Dunderdale, G.J., England, M.W. and Hozumi, A. (2017) Oil/Water Separation Techniques: A Review of Recent Progresses and Future Directions. Journal of Materials Chemistry A, 5, 16025-16058. https://doi.org/10.1039/C7TA02070H

[4] Allan, S.E., Smith, B.W. and Anderson, K.A. (2012) Impact of the Deepwater Horizon Oil Spill on Bioavailable Polycyclic Aromatic Hydrocarbons in Gulf of Mexico Coastal Waters. Environmental Science \& Technology, 46, 2033-2039.

[5] Latthe, S.S., Kodag, V.S., Sutar, R.S., Bhosale, A.K., Nagappan, S., Ha, C.S., Sadasivuni, K.K., Kulal, S.R., Liu, S. and Xiang, R. (2020) Sawdust-Based Superhydrophobic Pellets for Efficient Oil-Water Separation. Materials Chemistry and Physics, 243, Article ID: 122634. https://doi.org/10.1016/j.matchemphys.2020.122634

[6] Li, J., Xu, C.C., Guo, C.Q., Tian, H.F., Zha, F. and Guo, L. (2018) Underoil Superhydrophilic Desert Sand Layer for Efficient Gravity-Directed Water-in-Oil Emulsions Separation with High Flux. Journal of Materials Chemistry A, 6, 223-230. https://doi.org/10.1039/C7TA08076I 
[7] Yong, J.L., Chen, F., Yang, Q., Bian, H., Du, G.Q., Shan, C., Huo, J.L., Fang, Y. and Hou, X. (2016) Oil-Water Separation: A Gift from the Desert. Advanced Materials Interfaces, 3, Article ID: 1500650. https://doi.org/10.1002/admi.201500650

[8] Yang, S.L., Li, M.H., Fang, G.L., Xue, M. and Lu, Y.J. (2021) Flexible Cement-Sand Coated Cotton Fabrics with Superhydrophilic and Underwater Superoleophobic Wettability for the Separation of Water/Oil Mixtures and Oil-in-Water Emulsions. Colloids and Surfaces A: Physicochemical and Engineering Aspects, 608, Article ID: 125611. https://doi.org/10.1016/j.colsurfa.2020.125611

[9] Sawada, H., Chiba, M., Honma, G., Yamashita, K. and Suzuki, J. (2020) Preparation of Fluoroalkyl End-Capped Vinyltrimethoxysilane Oligomer/Micro-Sized Silica Composites Possessing Superoleophilic/Superhydrophobic Characteristic: Application to Selective Removal of Aromatic Compounds from Aqueous Methanol Solution by Using These Composites. Journal of Sol-Gel Science and Technology, 96, 636-648. https://doi.org/10.1007/s10971-020-05351-7

[10] Schwarzenbach, R.P., Escher, B.I., Fenner, K., Hofstetter, K.T.B., Johnson, C.A., von Gunten, U. and Wehrli, B. (2006) The Challenge of Micropollutants in Aquatic Systems. Science, 313, 1072-1077. https://doi.org/10.1126/science.1127291

[11] Alsbaiee, A., Smith, B.J., Xiao, L., Ling, Y., Helbling, D.E. and Dichtel, W.R. (2016) Rapid Removal of Organic Micropollutants from Water by a Porous $\beta$-Cyclodextrin Polymer. Nature, 529, 190-194. https://doi.org/10.1038/nature16185

[12] Muller, K., Faeh, C. and Diederich, F. (2006) Fluorine in Pharmaceuticals: Looking beyond Intuition. Science, 317, 1881-1886. https://doi.org/10.1126/science.1131943

[13] Isanbor, C. and O'Hagan, D. (2006) Fluorine in Medicinal Chemistry: A Review of Anti-Cancer Agents. Journal of Fluorine Chemistry, 127, 303-319.

https://doi.org/10.1016/j.jfluchem.2006.01.011

[14] Inoue, M., Sumii, Y. and Shibata, N. (2020) Contribution of Organofluorine Compounds to Pharmaceuticals. ACS Omega, 5, 10633-10640.

[15] Ogawa, Y., Tokunaga, E., Kobayashi, O., Hirai, K. and Shibata, N. (2020) Current Contributions of Organofluorine Compounds to the Agrochemical Industry. iScience, 23, Article ID: 101467. https://doi.org/10.1016/j.isci.2020.101467

[16] Liu, P.S., Niu, L.Y., Tao, X.H., Li, X.H., Zhang, Z.J. and Yu, L.G. (2018) Preparation of Superhydrophobic-Oleophilic Quartz Sand Filter and Its Application in Oil-Water Separation. Applied Surface Science, 447, 656-663. https://doi.org/10.1016/j.apsusc.2018.04.030

[17] Liu, S.M., Cai, T.L., Shen, X.Y., Huang, E.Z., Wang, Z. and Sun, Q.F. (2019) Superhydrophobic Sand with Multifunctionalities by $\mathrm{TiO}_{2}$-Incorporated Mussel-Inspired Polydopamine. Ceramics International, 45, 21263-21269. https://doi.org/10.1016/j.ceramint.2019.07.108

[18] Wang, B., Chen, C.L., Li, Z.X., Wu, J.F., Liu, X.L. and Wang, J.D. (2021) One-Step Fabrication Superhydrophobic Sand Filter for Capillary-Driven Separation of Water-in-Oil Emulsions. Chinese Journal of Chemical Engineering, 33, 70-75. https://doi.org/10.1016/j.cjche.2020.07.012

[19] Men, X.H., Ge, B., Li, P.L., Zhu, X.T., Shi, X.C. and Zhang, Z.Z. (2016) Facile Fabrication of Superhydrophobic Sand: Potential Advantages for Practical Application in Oil-Water Separation. Journal of the Taiwan Institute of Chemical Engineers, 60, 651-655. https://doi.org/10.1016/j.jtice.2015.11.015

[20] Liu, J.L., Zhu, X.F., Zhang, H.W., Wu, F.P., Wei, B.G. and Chang, Q. (2018) Superhydrophobic Coating on Quartz Sand Filter Media for Oily Wastewater Filtration. Colloids and Surfaces A: Physicochemical and Engineering Aspects, 553, 509-514. 
https://doi.org/10.1016/j.colsurfa.2018.06.007

[21] Yan, Y.Y., Zeng, X.J., Yang, K.Q., Zhou, P.Z., Xu, S.P., Pi, P.H., Li, H., Fang, J., Wang, S.N. and Wen, X.F. (2021) Janus Sand Filter with Excellent Demulsification Ability in Separation of Surfactant-Stabilized Oil/Water Emulsions: An Experimental and Molecular Dynamics Simulation Study. Journal of Hazardous Materials, 418, Article ID: 126346. https://doi.org/10.1016/j.jhazmat.2021.126346

[22] Liu, P.S., Niu, L.Y., Tao, X.H., Li, X.H. and Zhang, Z.J. (2019) Facile Preparation of Superhydrophobic Quartz Sands with Micro-Nano-Molecule Hierarchical Structure for Controlling the Permeability of Oil and Water Phase. Colloids and Surfaces A: Physicochemical and Engineering Aspects, 569, 1-9.

https://doi.org/10.1016/j.colsurfa.2019.02.035

[23] Sawada, H. (1996) Fluorinated Peroxides. Chemical Reviews, 96, 1779-1808. https://doi.org/10.1021/cr9411482

[24] Sawada, H. (2007) Synthesis of Self-Assembled Fluoroalkyl End-Capped Oligomeric Aggregates-Applications of These Aggregates to Fluorinated Oligomeric Nanocomposites. Progress in Polymer Science, 32, 509-553. https://doi.org/10.1016/j.progpolymsci.2007.02.002

[25] Sawada, H. (2007) Development of Fluorinated Polymeric Functional Materials Using Fluorinated Organic Peroxide as Key Material. Polymer Journal, 39, 637-650. https://doi.org/10.1295/polymj.PJ2006242

[26] Sawada, H. (2012) Development of Fluorinated Polymeric Functional Materials Using Fluorinated Organic Peroxide as Key Material. Polymer Chemistry, 3, 46-65.

[27] Sawada, H. and Nakayama, M. (1991) Synthesis of Fluorine-Containing Organosilicon Oligomers. Journal of the Chemical Society, Chemical Communications, 1991, 677-678. https://doi.org/10.1039/c39910000677

[28] Sawada, H., Suzuki, T., Takashima, H. and Takishita, K. (2008) Preparation and Properties of Fluoroalkyl End-Capped Vinyltrimethoxysilane Oligomeric Nanoparticles-A New Approach to Facile Creation of a Completely Superhydrophobic Coating Surface with These Nanoparticles. Colloid and Polymer Science, 286, 1569-1574. https://doi.org/10.1007/s00396-008-1926-7 